\title{
Bioavailability Improvement Strategies for Poorly Water-Soluble Drugs Based on the Supersaturation Mechanism: An Update
}

\author{
Meiyan Yang, Wei Gong, Yuli Wang, Li Shan, Ying Li, Chunsheng Gao \\ Pharmacology and Toxicology, Beijing 100850, China \\ Received, January 13, 2016; Revised, May 5, 2016; Accepted, May 16, 2016; Published, May 16, 2016.
}

State key Laboratory of Toxicology and Medical Countermeasures, Department of Pharmaceutics, Beijing Institute of

\begin{abstract}
The formulation development for poorly soluble drugs still remains a challenge. Supersaturating drug delivery systems (SDDS) or drug delivery systems based on supersaturating provide a promising way to improve the oral bioavailability of poorly water-soluble drugs. In supersaturable formulations, drug concentration exceeds the equilibrium solubility when exposed to gastrointestinal fluids, and the supersaturation state is maintained long enough to be absorbed, resulting in compromised bioavailability. In this article, the mechanism of generating and maintaining supersaturation and the evaluation methods of supersaturation assays are discussed. Recent advances in different drug delivery systems based on supersaturating are the focus and are discussed in detail.
\end{abstract}

This article is open to POST-PUBLICATION REVIEW. Registered readers (see "For Readers") may comment by clicking on ABSTRACT on the issue's contents page.

\section{INTRODUCTION}

Currently, with the development of combinatorial chemistry and high-throughput screening, it is estimated that $25 \%-40 \%$ of the drug substances and almost $70 \%$ of the potential drug candidates exhibit poor solubility characteristics, which creates a problem with slow absorption and low bioavailability $(1,2)$. The formulation development for poorly soluble drugs (PWSD) still remains a challenge (3).To improve the solubility and dissolution patterns of these PWSD, several attempts have been reported, including crystal modification, amorphization, cyclodextrin complexes, and solid dispersions (SDs) (4-7).

According to the Noyes-Whitney equation, solubility is one of the major driving forces of dissolution. However, because the absorption of a drug in the gastrointestinal tract is limited not by the equilibrium solubility but by the fraction dissolved, the traditional solubilization methods that can only increase the equilibrium solubility cannot facilitate cell permeation (8). The formulation development for PWSD plays a major role in determining the rate and extent of absorption of such drugs from the gastrointestinal tract (9). More and more results have shown that the drug could exist in a state of solution at a concentration above their saturation solubility, that is, supersaturation
(10). The transmembrane transport effect of the drugs in supersaturation, as discovered by Higuchi, was initially and widely investigated in the field of transdermal drug delivery (11-14). With further understanding, it was found that the drug concentration of the supersaturable formulations always exceeds the equilibrium solubility when exposed to gastrointestinal fluids $(10,15)$. It was first proved by Frank et al. that the supersaturated (highly dissolved and dispersed) state of a drug could significantly increase the Caco-2 cell permeation of poorly water-soluble drugs (16). Accordingly, the supersaturating drug delivery systems (SDDS) or drug delivery systems based on supersaturating, which contain the drug in a high energy form of supersaturation, provide a promising way to improve the oral bioavailability of the poorly water-soluble drugs $(10,17,18)$. The point of the poor solubility problem is now shifting from formulating to further basic understanding of the supersaturation mechanism. Therefore, it is important and necessary to provide an update on the recent advances on this topic. In this article, recent advances in drug delivery systems based on supersaturation are reviewed.

Corresponding Author: Prof. Chunsheng Gao, Beijing Institute of Pharmacology and Toxicology, Beijing 100850, China; Email: gaocs@bmi.ac.cn. 
We will discuss the mechanism of generating and maintaining supersaturation and illustrate the precipitation inhibitors with examples. Next, methods of evaluating supersaturation assays will be discussed. Finally, different drug delivery systems based on supersaturating, such as solid dispersions, supersaturated self-emulsifying drug delivery systems, non-inclusion complexes of cyclodextrin, nanodrugs, and others will be the focus and are discussed in detail.

\section{Mechanism of supersaturation}

For SDDS, the degree of supersaturation is the driving force of drug precipitation, and the higher is the degree of supersaturation, the easier the precipitation. The degree of supersaturation is always expressed by the supersaturation ratio $S$ :

$$
S=\frac{C}{C \mathrm{eq}}
$$

where $C$ is the drug concentration and $C$ eq is the equilibrium solubility. Additionally, the relative supersaturation index $\sigma$ could be used to express the supersaturation:

$$
\sigma=S-1=\frac{C-C \text { eq }}{C \text { eq }}
$$

$S$ and $\sigma$, solutions that are unsaturated, saturated or supersaturated can be defined as $S<1(\sigma<0), S=1$ $(\sigma=0)$, or $S>1(\sigma>0)$, respectively (10).

Additionally, the bioavailability improvement mechanisms of the acidic and basic drugs are different. For poorly water-soluble acidic drugs, the enhancement of in vivo performance is due to the redissolving of the amorphous form in the stomach during transit to the more neutral environment of the duodenum (19). For poorly water-soluble weakly basic drugs, the self-association of a stable supersaturated drug solution in an acidic aqueous solution can increase its oral absorption by supersaturation and precipitation resistance at the intestinal $\mathrm{pH}(20)$.

\section{Spring and parachute theory}

To improve oral absorption of PWSD, two essential steps need to be considered: generation and maintenance of the metastable supersaturated state. The "spring and parachute" theory, which was proposed by Guzmán, is widely used to describe the state as illustrated in Fig. 1 (21). The high energy supersaturated form (as compared to the crystalline powder) is thermodynamically unstable and has a tendency to precipitate and crystallize, that is, the "spring". However, if the supersaturated state in the gastrointestinal tract is maintained long enough, it could increase drug absorption and then improve oral availability. The precipitation inhibitors ("parachutes") are commonly used to maintain a high concentration and inhibit drug precipitation for an extended period of time $(10,21)$.

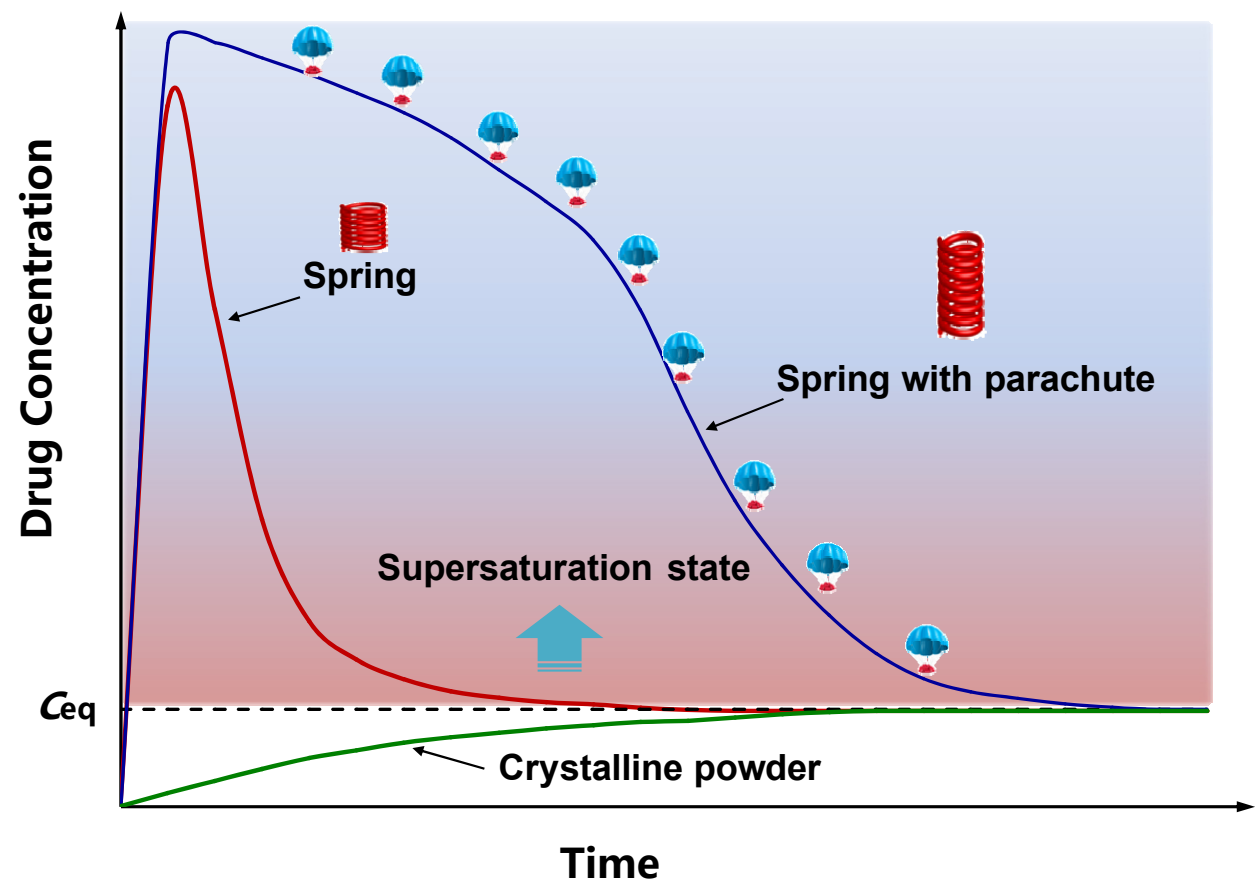

Figure. 1 Illustration of the spring and parachute theory. Reproduced with modification from Brouwers et al. (2009). 
The abovementioned patterns were confirmed in several reports. For amorphous systems, the supersaturation generation showed nonlinear rate profiles, which displayed excessively high initial supersaturation followed by a rapid decrease in drug concentration owing to supersaturation-induced precipitation and the drug-polymer-water interaction (22-24).

Compared with traditional solubilized formulations (emulsified oil, mixed micelles, etc.), the supersaturation drug delivery system is a type of dispersion at the molecular level. Although it is difficult to distinguish solubilization and supersaturation in the solution completely, a lot of research results show that supersaturation plays an important role in improving bioavailability (25). The differences in the two systems are summarized in Table $1(10,26,27)$.

\section{Precipitation inhibitors}

To inhibit drug precipitation and maintain the metastable supersaturation state, and thus improve oral bioavailability, precipitation inhibitors (PIs) are commonly needed and considered to be the key factors in the development of SDDS. The precipitation inhibition mechanism of the PIs is interfering with the nucleation and crystal growth process of the drug though thermodynamics or kinetics. The thermodynamic process is mainly to improve the solubility of the drug so as to reduce the degree of supersaturation and slow the rate of nucleation and crystal growth. The dynamic process is mainly to inhibit crystal nucleus formation or crystal nucleus growth in the supersaturated state $(10,15)$.

The commonly used different types of PIs include polymers, surfactants, and cyclodextrins
(CD), among others. Of these PIs, polymers such as HPMC, HPMCAS and PVP are commonly used and mainly act through the above-mentioned dynamic process $(15,28)$. The precipitation inhibition mechanism at high and low degrees of supersaturation is different, that is, inhibiting the growth of crystallization and inhibiting the aggregation of the crystallization surface, respectively (29).

The types of PIs always affect the degree of supersaturation. The commonly used HPMC is believed to inhibit precipitation with greater hydrogen bonding interactions, thereby maintaining a supersaturated solution over an extended period of time $(15,17)$. However, for tacrolimus SD, the types of PIs have little effect on the degree of the supersaturation but affect the maintenance time of the supersaturation (30). Moreover, the conformation of a polymer adsorbed to a crystal surface has an effect on crystal growth inhibition. For instance, the differences in the conformation of HPMCAS adsorbed to felodipine at $\mathrm{pH} 3$ and $\mathrm{pH}$ 6.8 are significant. The globule formation at $\mathrm{pH} 3$ might leave many crystal nucleus growth sites open and thus reduce the crystallization inhibition effect (31).

Up to now, the mechanism through which the PIs inhibited drug crystallization was not fully clear, although many instrumental analysis methods such as powder X-ray diffraction (PXRD), differential scanning calorimetry (DSC), and Fourier transformed infrared spectroscopy (FTIR) have been used to study the interaction of drugs and PIs. The known mechanisms include hydrogen bonding and hydrophobic interaction, space steric hindrance, polymer solution viscosity, and others (15).

Table 1 Differences between the solubilization and supersaturation formulations.

\begin{tabular}{lll}
\hline Options & Solubilization formulations & Supersaturation formulations \\
\hline Mechanism & Maximizing solubilization & Supersaturating generation and maintenance \\
Process & Dynamic process & Thermodynamic or dynamic process \\
Application & Not applicable to very poor solubility drugs & Applicable to very poor solubility drugs \\
Uptake & Low free drug fraction & High free drug fraction \\
Composition & High amount of surfactant & $\begin{array}{l}\text { Low amount of surfactant, high drug-loading } \\
\text { and lower toxicity }\end{array}$ \\
\hline
\end{tabular}




\section{Supersaturation assay}

Drug dissolution and permeability in the gastrointestinal tract are two important driving forces for oral absorption of active pharmaceutical ingredients. Traditionally, the in vitro test was commonly used for quality control (QC). Because the effect of gastrointestinal physiological conditions on supersaturation is very complex, the correlations among supersaturated parameters in vitro and in vivo need further study (32). Therefore, the establishment of an appropriate in vitro prediction model is very much desirable in the supersaturation system (33).

Poorly soluble weak bases typically exhibit high solubility under fasted gastric conditions. The in vitro $\mathrm{pH}$-effect of the weak base was correlated linearly with the clinical $\mathrm{pH}$ effect based on the $\mathrm{C}_{\max }$ ratio and had a non-linear relationship based with the AUC ratio. Thus, a method to systematically assess the risk of a clinical $\mathrm{pH}$ effect for new molecular species is needed (34). The supersaturation and precipitation during the fasted state of gastric emptying may have an essential influence on oral drug absorption and thus on in vivo drug performance, such as that seen with cinnarizine with moderate permeability (35). Additionally, the in vitro conditions (dispersive versus digestive) largely influence the solid-state properties of precipitating weak bases (36). For dipyridamole, the supersaturation ratios are up to 11-fold, and the supersaturation state has been maintained for up to $120 \mathrm{~min}$. Moreover, the crystal growth, rather than nucleation, is the rate-limiting step for the precipitation of the drug (37). For ketoconazol (BCS 2), because the high luminal concentration caused by supersaturation saturated the metabolic enzymes, the correlation of in vitro dissolution and in vivo absorption was poor (32).

To improve the predictability of the in vitro model, running the dissolution at a higher paddle speed, for a longer duration or in a non-sink condition was recommended (38). Reviews by Kostewicz described the in vitro models for the prediction of in vivo performance of oral dosage forms. A novel miniscale biphasic dissolution model with $\mathrm{pH}$ shift was reported and was superior to a single phasic dissolution in predicting in vivo precipitation of dipyridamole (39). Additionally, in vitro lipolysis is widely utilized for predicting in vivo performance of oral lipid-based formulations (LBFs) $(40,41)$. However, it is worth noting that the in vitro performance is not always reproduced in vivo independent of the initial physical state of the drug. In a continuous absorption environment, the drug supersaturation was considerably lower compared to in vitro lipolysis (non-sink), which was beneficial for predicting LBF performance in vivo (42). Therefore, a combination of physico-chemical measurements, in vitro tests, in vivo methods, and physiology-based pharmacokinetic modeling is expected to create a knowledge platform $(33,43)$.

Despite several efforts made in studies of precipitation inhibitors and supersaturable formulations, little is known about the mechanistic aspects of inhibition, especially at the molecular level (15). The determination of drug concentration in a supersaturated solution is still a problem (44). At present, the centrifugation or membrane filtration methods (including $0.22-\mu \mathrm{m}$ or $0.45-\mu \mathrm{m}$ membranes) are commonly used. Because of the existence of the cosolvent or the solubilizer, the determined drug concentration is a more micellized drug or drug compound, rather than the drug at the molecular level. The effective method to distinguish them has been insufficient until now (10).

Recently, novel instrumental analytical methods have been used to study the mechanism of precipitation inhibition in vitro, such as synchrotron radiation (8), in situ Raman spectroscopy (45), NMR (46), turbidity and supernatant microplate assay combinations (47), and pulsatile microdialysis (44). These technologies could be helpful for studying the mechanism of inhibition, especially at the molecular level.

In addition to the in vitro dissolution models, the intestinal supersaturation and enhanced absorption were confirmed in vivo (human) by intraluminal sampling of duodenal fluids upon oral intake of an abiraterone acetate tablet by healthy volunteers (48). However, the multitude of interactions between drugs, formulation factors and the gastrointestinal environment, combined with the highly fluctuating intraluminal environment, make it challenging to interpret gastrointestinal concentration-time profiles. The combination of simultaneous systemic concentration assessment further helps to identify those processes, determine the rate and/or extent of absorption, and assess inter-individual variability (49).

\section{Recently available drug delivery systems based on supersaturating}

In recent years, to improve the in vitro dissolution and in vivo bioavailability, the application of 
supersaturating drug delivery systems is attracting increasing attention (50). The key factors in the development of SDDS are the generation and maintenance of the supersaturation state. The recent progress in different types of drug delivery systems based on supersaturation is shown in Fig. 2 and discussed below.

\section{Solid dispersions}

Solid dispersions (SDs) have been most extensively studied in the SDDS research field, which is the combination of a rapidly dissolving and supersaturating "spring" with a precipitation retarding "parachute". Dispersing amorphous or microcrystalline drugs into one or several hydrophilic carriers (such as PVP, PEG, methyl acrylate, cellulose derivatives, inulin, etc.), which is shown in Fig. 3, can improve the dissolution rate or produce controlled-release by increasing the supersaturated drug concentration $(51,52)$. With the increase in FDA approval of products based on SD technology, SDs are being used with increasing frequency for poorly soluble pharmaceutical compounds in development $(53,54)$. A review by Newman discusses the methods of preparation and characterization of SDs with an emphasis on understanding and predicting stability (51).

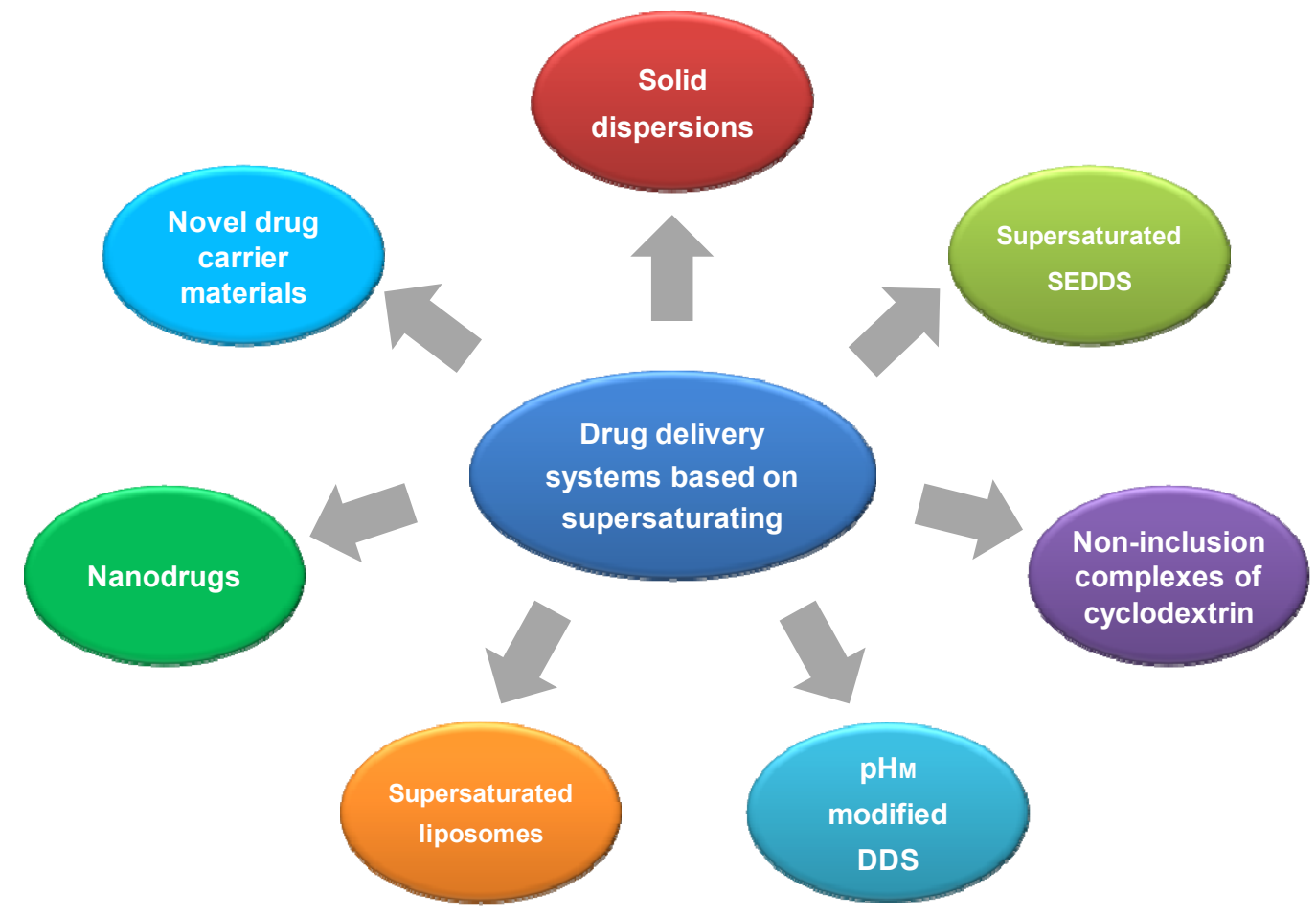

Figure. 2 Types of drug delivery systems based on supersaturation.

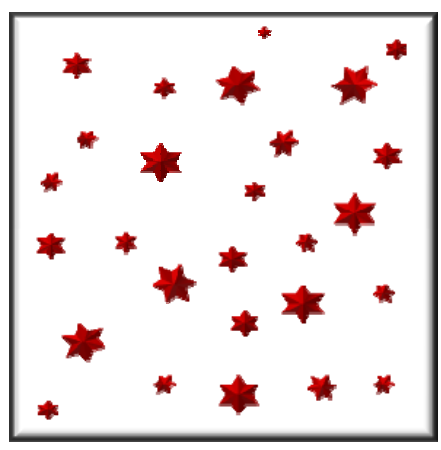

Microcrystalline dispersion

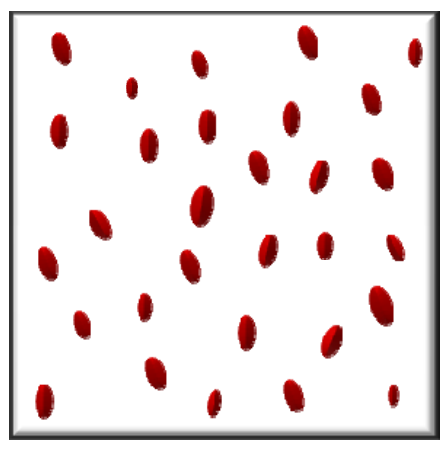

Amorphous dispersion

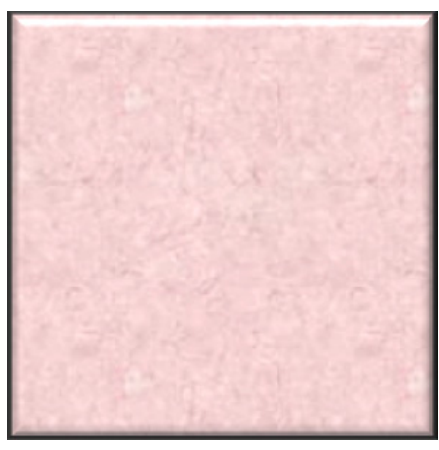

Molecular dispersion

Figure. 3 Illustration of the solid dispersions in the carriers at different dispersion levels. 


\section{Phase transition or separation}

The supersaturated solutions generated by dissolution of some SDs can undergo a phase transition to a colloidal, disordered, drug-rich phase when the concentration exceeds the saturation solubility of the drug. It was found that highly supersaturated solutions of telaprevir underwent a glass-liquid phase separation (GLPS) with a glass transition temperature of $52{ }^{\circ} \mathrm{C}$ (55). Raina found that a liquid-liquid phase separation (LLPS) phenomenon existed in a supersaturated solution after the dissolution test, and the upper limit level of the drug membrane transport was determined by the LLPS (56). The LLPS was also generated when danazol was added to aqueous media at concentrations above the amorphous solubility, and the addition of polymers greatly extended the lifetime of the supersaturated two-phase system (57). Additionally, the amorphous SD formulations of a poorly water-soluble drug, MK-0364, exhibit characteristics of a single-phase glass, including an amorphous halo (58). When the level of the precipitation inhibitor D-a-tocopheryl polyethylene glycol 1000 (TPGS 1000) is above $10 \%$, the inclusion of TPGS 1000 in the PVPVA 64 carrier matrix will affect the dispersion of itraconazole at the molecular level, leading to the formation of drug clusters (59). However, the results of the phase separation are different at the different dissolution stages. In the early stage of drug dissolution $(1 \mathrm{~h})$, this phase separation can promote drug dissolution due to the solubilization effect of TPGS1000. In the late stage of drug dissolution, the phase separation effect will lead, in contrast, to a drug precipitate (12).

\section{Factors influence supersaturation}

The in vitro drug dissolution characteristics of SDs depend largely on the degree and maintenance time of supersaturation, which is determined by the formulation composition and preparation technology (53).

\section{(1) Formulation aspects}

The polymer type and drug/polymer ratio are very important for maintaining the stability of the supersaturated state. The degree of supersaturation increased significantly with increases in polymer content within the solid dispersion $(60,61)$.

HPMC is a commonly used carrier in SDs. Of three different carriers (HPMC, PVP, and PEG6000), formulations containing HPMC maintained the longest supersaturated time. A pharmacokinetic study in beagle dogs showed that the $\mathrm{C}_{\max }$ and $\mathrm{AUC}$ of the HPMC formulation increased 10 times compared to the crystal drug (17). Recently, Sporanox ${ }^{\circledR}$ (a type of capsule) has been used in the dispersion of itraconazole based on the supersaturation mechanism, which consisted of a sugar pill coated with the HPMC solid dispersion (26).

Among 41 types of precipitation inhibitors (including polymer and surfactant, carboxylic acid, etc.), the precipitation inhibitor effect of enteric polymer hydroxypropylmethylcellulose-acetate (HPMCAS) is the best (62). Similar results showed that HPMCAS systems performed better than or at least comparably to PVPVA systems, regardless of the drug loading or dose (23). Additionally, site-specific delivery could be obtained using enteric polymer HPMCAS or Eudragit L 100-55 $(63,64)$.

To obtain further stable supersaturated states, the combination of two polymers with drug-polymer interaction offers synergistic enhancement in amorphous stability and dissolution in ternary solid dispersions (65). For example, in the Eudragit L system, Carbopol1 974P can be used as a stabilizer (66). Other results have suggested that the Eudragit has the fastest in vitro dissolution pattern because of its high degree of supersaturation among the three PIs (PEG6000, PVP K30 and Eudragit) (67). Valsartan-HPMC-poloxamer 407 nanoparticles using the supercritical antisolvent (SAS) process exhibited faster drug release (up to $90 \%$ within 10 minutes under all dissolution conditions) and higher oral bioavailability than the raw material, with an approximately 7.2-fold higher maximum plasma concentration (68). With ternary solid dispersions of the drugs HPMCAS and hydroxypropylcellulose (HPCSSL), tailored release profiles with superior supersaturation over the applied pH-range could be obtained (64).

Interestingly, besides the carriers, in a first-reported fixed dose combination of ritonavir and darunavir dispersible powders, it was found that the presence of darunavir always decreased the supersaturation level of ritonavir and vice versa, regardless of which polymer was used (69). 


\begin{tabular}{|c|c|c|c|}
\hline Drug & Precipitation Inhibitors & In vitro or in vivo Performance & References \\
\hline MK-0364 & Copovidone, HPMCAS & $\begin{array}{l}\text { Oral absorption in monkeys marginally } \\
\text { greater exposure with longer } \mathrm{T}_{\max } \text { compared to } \\
\text { liquid-filled capsule reference }\end{array}$ & $(58)$ \\
\hline Cilostazol & $\begin{array}{l}\text { Povidone as carrier, } \\
\text { hydrogenated vegetable oil as } \\
\text { wax matrix former, NaCMC as } \\
\text { disintegrant }\end{array}$ & $\begin{array}{l}\text { Supersaturation state allowed drug release by } \\
\text { diffusion rather than disintegration-regulated } \\
\text { release }\end{array}$ & $(60)$ \\
\hline $\begin{array}{l}\text { Dipyridamole } \\
\text { or Griseofulvin }\end{array}$ & HPMCAS, HPCSSL & $\begin{array}{l}\text { Combination of two polymers showing } \\
\text { tailored release profiles with superior } \\
\text { supersaturation over the applied pH range }\end{array}$ & (64) \\
\hline Indomethacin & Eudragit E100, PVP K90 & $\begin{array}{l}\text { Combination of two polymers showing } \\
\text { enhancement in amorphous stability and } \\
\text { dissolution }\end{array}$ & $(65)$ \\
\hline $\begin{array}{l}\text { Patchouli } \\
\text { alcohol }\end{array}$ & PEG, PVP K30, Eudragit ${ }^{\circledR}$ & $\begin{array}{l}\text { Highest concentration of supersaturation of } \\
\text { the drug was obtained from the Eudragit } \\
\text { formulation }\end{array}$ & $(67)$ \\
\hline $\begin{array}{l}\text { Ritonavir \& } \\
\text { darunavir }\end{array}$ & HPMC, PVP, PVPVA 64 & $\begin{array}{l}\text { Darunavir decreased the supersaturation level } \\
\text { of ritonavir and vice versa regardless of which } \\
\text { polymers were used }\end{array}$ & (69) \\
\hline Felodipine & HPCSSL, PVPVA & $\begin{array}{l}\text { Displayed superior drug dissolution and } \\
\text { partitioning compared to the pure crystalline } \\
\text { drug }\end{array}$ & $(70)$ \\
\hline Curcumin & $\beta-\mathrm{CD}, \mathrm{HA}, \mathrm{HPMC}$ & $\begin{array}{l}\text { The lyophilized SDs were photolabile but } \\
\text { thermally stable and dissolved rapidly }\end{array}$ & (73) \\
\hline Itraconazole & $\begin{array}{l}\text { Dextran sulfate as the } \\
\text { polyelectrolyte (ITZ nanoplex) } \\
\text { or HPMC as the surface } \\
\text { stabilizer (nano-ITZ) }\end{array}$ & $\begin{array}{l}\text { Both strategies share similar morphology; the } \\
\text { nanoplex also exhibits superior amorphous } \\
\text { state stability compared to the nano-ITZ }\end{array}$ & (74) \\
\hline $\begin{array}{l}\text { Acetyl-11-keto } \\
-\beta \text {-boswellic } \\
\text { acid }\end{array}$ & $\begin{array}{l}\text { AQOAT®-LF, AQOAT®-MF, } \\
\text { Eudragit }{ }^{\circledR} \text { L100-55, Soluplus }\end{array}$ & $\begin{array}{l}\text { Significantly enhanced absorption in vivo } \\
\text { compared to the neat, active substance }\end{array}$ & $(75)$ \\
\hline
\end{tabular}

\section{(2) Methods of preparation}

The processing methods used to prepare the solid dispersions (such as hot melt mixing, ball milling, spray drying, and film casting) may play a role in the stabilization of amorphous drugs in supersaturated SDs. Hot melt mixing (HMM) has traditionally been used by heating mixtures of the drug and carrier to a molten state, followed by resolidification via cooling, and this process can make a drug under a critical supersaturation state avoid nucleation of the drug more effectively (70,71). Amorphous ITZ was physically unstable and recrystallized at high temperature and humidity levels. The supersaturation of HMT SDs was improved for the stability samples of ITZ: HPMCAS-LF, in which no physical or chemical instability was observed. The improvement in supersaturation was attributed to the temperature and moisture activated electrostatic interactions between the drugs and their counterionic polymers (66). Ball milling provided better reproducibility. However, an analysis of residuals revealed a systematic error. Therefore, other techniques such as spray-drying or potentially film casting should be used to prepare the amorphous dispersions when performing solubility measurements $(53,72)$. Solid-state structures of spray-dried dispersions showed a single-glass transition of a homogeneous mixture of drug/polymer. Forced aggregation of the polymer into regular micelle structures was found to be a critical factor in increasing the dissolution rate and supersaturation maintenance of spray-dried SDs (63). Lyophilization is an alternative to develop rapid-dissolving formulations (73).

Some other processing techniques were used to prepare SDs and produced positive results, such as the amorphization strategies (74), KinetiSol ${ }^{\circledR}$ Dispersing (KSD) (75), and others.

\section{Supersaturated self-emulsifying drug delivery systems}

Traditional self-emulsifying drug delivery systems (SEDDS) will occasionally precipitate after administration due to the dilution effect of 
the fluid. The solubilization method is commonly used to avoid precipitating. However, the bioavailability improvement effects are limited because the solubilization cannot increase the amount of free drug, especially for some very poorly soluble hydrophilic drugs. A review by Dokania describes the limitations of SEDDS (such as in vivo drug precipitation, formulation handling issues, etc.), and the inclusion of polymers or other PIs within lipid-based formulations helps to maintain drug supersaturation after dispersion. Therefore, to reduce the amount of the surfactant and improve bioavailability, PIs are added to prepare the supersaturated self-emulsifying drug delivery systems (S-SEDDS) (76).

S-SEDDS were first reported to improve the bioavailability of the poorly water-soluble antitumor drug paclitaxel (water solubility $<1$ $\mu \mathrm{g} / \mathrm{mL}$ ) (77). Compared with traditional SEDDS using emulsification and solubilization, the amount of the surfactant of S-SEDDS was lower with high supersaturation, which was maintained long enough for drug absorption. The results show that the addition of 5\% HPMC can significantly inhibit the dilution effect of fluids in paclitaxel SEDDS, and the in vivo bioavailability in rat was increased 4.7 times more than Taxol ${ }^{\circledR}$ (78). The supersaturatable formulation studies of drug candidates PNU-91325 and AMG 517 also obtained similar results $(79,80)$.

To further improve the precipitation inhibition effect, supersaturatable self-microemulsifying drug delivery systems (S-SMEDDS) and supersaturable self-nanoemulsifying drug delivery systems (S-SNEDDS), which are formed with microemulsions and nanoemulsions, respectively, have emerged as vital strategies. For S-SMEDDS of indirubin, the high supersaturation degree after dilution can be maintained up to $2 \mathrm{~h}$ with a $0.5 \%$ level of PIs (PVP K17, HPMC or PEG4000). The in vivo pharmacokinetics in male rats showed that the bioavailability of the formulation with PVP K17 was increased by $30 \%$ compared to formulations without PVP K17 and increased several times more than HPMC or PEG4000 formulations (81). In addition to the precipitation inhibition effect, the inclusion of HPMC E5LV in the S-SNEDDS can significantly reduce the excretion effect of P-glycoprotein and multi-resistant proteins to improve systemic exposure levels of the model drug ezetimibe (82, 83). The S-SNEDDS formulation of trans-resveratrol (t-RVT) resulted in the formation of a nanoemulsion, and the pharmacokinetic study indicated that the $\mathrm{AUC}_{0-8 \mathrm{~h}}$ of the S-SNEDDS formulation increased by nearly 1.33 -fold in the presence of the precipitation inhibitor HPMC (84).

Stability is a problem to scale up liquid SEDDS formulations. Transforming the liquid SEDDS into solid SEDDS using spray drying, spray congealing, adsorption onto solid carriers, melt granulation and hot-melt extrusion provides an alternative for the liquid formulations (4).

\section{Non-inclusion complexes of cyclodextrins} Cyclodextrins (CDs) are cyclic oligosaccharides composed of 6-8 dextrose units ( $\alpha-, \beta-$, and $\gamma$-cyclodextrins, respectively) joined through 1-4 $\mathrm{C}-\mathrm{C}$ bonds, which form a structure with a lipophilic interior and hydrophilic exterior. Cyclodextrins can be used for the solubilization of poorly water-soluble drugs due to the inclusion effect by Vander Waals interaction, hydrogen bonding and charge transfer interactions $(4,85$, 86). However, cyclodextrins are also known to form non-inclusion complexes $(87,88)$. It has been shown that both inclusion and non-inclusion complexes always coexist in saturated aqueous solutions $(89,90)$. The hydroxy groups on the outer surface of the cyclodextrin molecule are able to form hydrogen bonds with other molecules, and cyclodextrins can, like non-cyclic oligosaccharides and polysaccharides, form water-soluble complexes with lipophilic water-insoluble compounds, that is, non-inclusion complexes $(89,91)$. The process is shown in Fig. 4. Moreover, the presence of the dextran backbone structure does not affect the stability of the $\beta-\mathrm{CD} /$ drug complex compared to native $\beta-\mathrm{CD}$ and commercially available derivatives (92). Similar to the lipid formulations, the non-inclusion complexes of cyclodextrin always have a high drug/excipient ratio (93).

The mechanism of precipitate inhibition of $\mathrm{CD}$ is also a "spring" and "parachute" model, which is a both a thermodynamic and dynamic process. On the one hand, CD can increase the apparent equilibrium solubility and thus reduce the degree of supersaturation. In addition, CD can increase the solvation effect of the drug molecules in the solution and can increase the activation energy of the desolvation effect in the process of crystal growth $(87,89)$. Finally, cyclodextrin can act as a kosmotrope (order-maker), which is the non-inclusion mechanism, therefore leading to an increased concentration of free drug and uptake accordingly (94). This process could explain why the value of the equilibrium constant for complex formation is sometimes concentration-dependent and why their numerical value is frequently 
dependent on the method applied (95). This precipitation inhibition effect can be applied to improve bioavailability in vivo (94).

\section{Microenvironment pH-modified drug delivery systems}

The microenvironment $\mathrm{pH}\left(\mathrm{pH}_{\mathrm{M}}\right)$ could be described as a microscopic layer surrounding a solid particle in which the solid forms a saturated solution with the adsorbed water $(96,97) . \mathrm{pH}_{\mathrm{M}}$ modifier technology, which involves adding an acidifier or alkalizer to formulations containing weakly basic or acidic drugs, respectively, was used extensively to improve the solubility, obtain $\mathrm{pH}$ independence, and achieve sustained drug release $(98,99)$. Especially for weakly basic drugs, the use of acidic excipients enabled a more robust formulation less susceptible to variance in gastric $\mathrm{pH}$, improved the observed variability, and achieved adequate exposure under high gastric $\mathrm{pH}$ conditions (100).

With citric acid as the $\mathrm{pH}_{\mathrm{M}}$ modifier and the polymer PVP as the precipitation inhibitor, the supersaturated state of weakly basic GT0918 was maintained for at least $2 \mathrm{~h}$ without any aggregation and precipitation, and thus, the bioavailability was improved significantly, which was attributed to crystal growth inhibition of the polymer. Fig. 4 shows the color changes by the indicator bromophenol blue (changing range $\mathrm{pH}$
2.8-4.6) for the $\mathrm{pH}_{\mathrm{M}}$-SD tablets and the dissolution media at different times, which indicated that an acid environment inside of the tablet was generated (101). To improve the in vitro drug release of weakly acidic AMG009, the alkalify agent was added to the HPMC K100LV matrix, and drug release was improved from less than $4 \%(5 \mathrm{~h})$ to above $60 \%$. Additionally, the HPMC K100LV in the sodium carbonate layer has an essential effect on alkalify agent leakage and $\mathrm{pH}_{\mathrm{M}}$ maintenance (102). The mechanism of the $\mathrm{pH}_{\mathrm{M}}$ modification might be preventing or slowing the crystallization of the drug in the microenvironment that governs the dissolution of the drug from the solid dosage forms (103).

\section{Nanodrugs}

\section{Drug nanocrystals}

According to the Noyes-Whitney equation, the smaller the particle size, the larger is the specific surface area. Therefore, reducing the particle size even to the nanoscale level can improve drug loading, in vitro dissolution and in vivo bioavailability (104). In recent decades, nanocrystals have been widely investigated, and there are some products on the market that can be applied by oral, parenteral, pulmonary, dermal and ocular routes.

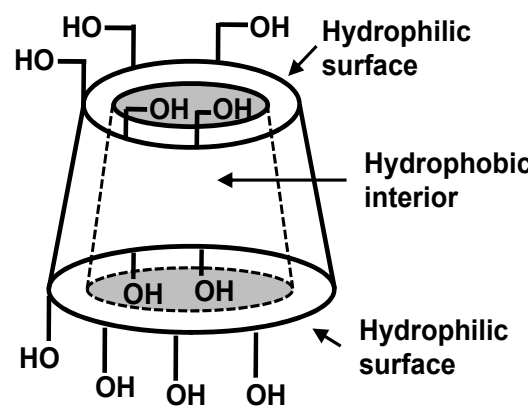

Cyclodextrin

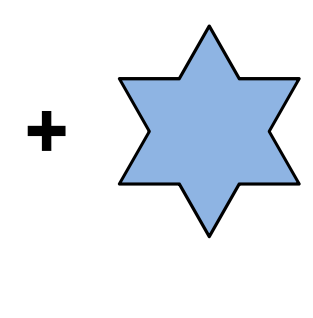

Drug
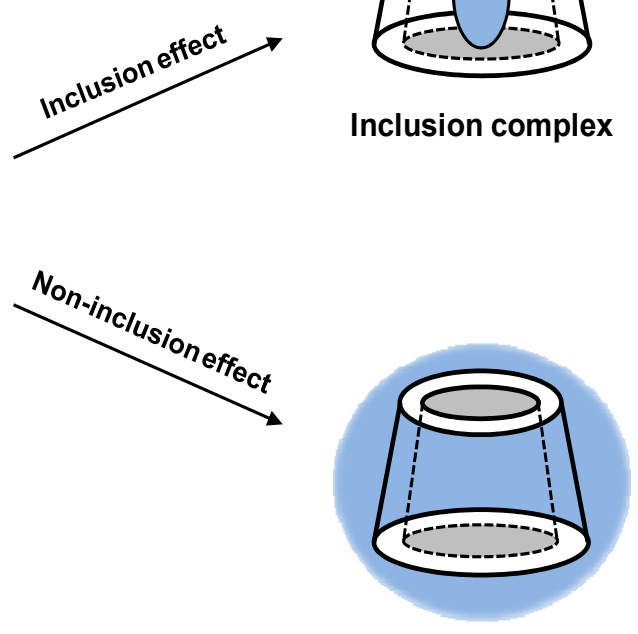

Non-inclusion complex

Figure 4 Illustration of inclusion complexes and non-inclusion complexes of cyclodextrins. 
The preparation methods of nanocrystals include the following: bottom-up method (such as anti-solvent precipitation and droplet controlled evaporation), top-down method (such as milling and homogenization) and the combined use of both methods $(105,106)$. Reviews by Pawar describe the in vivo fate, targeting and applications in drug delivery of nanocrystal technology (107).

Dalvi and Dave studied the nuclear dynamics of four drugs, namely itraconazole, griseofulvin, ibuprofen and sulfamethoxazole, with the anti-solvent precipitation method. The results showed that the drug nucleation rate increased significantly in the presence of the ultrasonic and the precipitation inhibitor HPMC. The reason is that the ultrasonic can improve the rate of diffusion, and HPMC can reduce the interfacial tension of the solid-liquid. Additionally, the lower the solubility of a drug, the easier it is to reduce the interfacial tension and thus to generate the drug particles at a sub-micron scale (108). The incorporation of polyethylene glycol (PEG) or its methoxylated derivative (MPEG) as a stabilizer can produce smaller NPs with narrower particle size distribution and enhanced apparent solubility (109).

It is well known that nanocrystals are thermodynamically and dynamically unstable systems, and the physical stability problem has been the bottleneck of their application and industrialization. The particle size of nanocrystals in aqueous suspensions may increase during placement due to the supersaturation and the recrystallization into larger particles, also known as Ostwald ripening. These processes ultimately lead to the viability of the formulations and the irreversible loss of formulation integrity (110). To solve this problem, the solidification strategy may be the future development for nanocrystals (111).

\section{Drug nanoparticle complexes}

The amorphous nanoparticle complex (nanoplex) prepared by electrostatic complexation of drug molecules with oppositely charged carriers (such as dextran sulfate or carrageenan) represents a promising bioavailability enhancement strategy for poorly soluble drugs owing to their high supersaturation generation ability and simple preparation (74). Because the supersaturation of the amorphous nanoparticles in their aqueous suspension is always adversely affected after drying, only one adjuvant type is always ineffective in preserving the supersaturation. Therefore, the dual-adjuvant formulations (i.e., trehalose-HPMC and mannitol-HPMC) were used and proved to preserve the supersaturation generation ability after drying effectively (112).

In addition, a novel porous hollow fiber (Nylon-6) using an antisolvent crystallization method was reported to generate polymer-coated drug crystals.

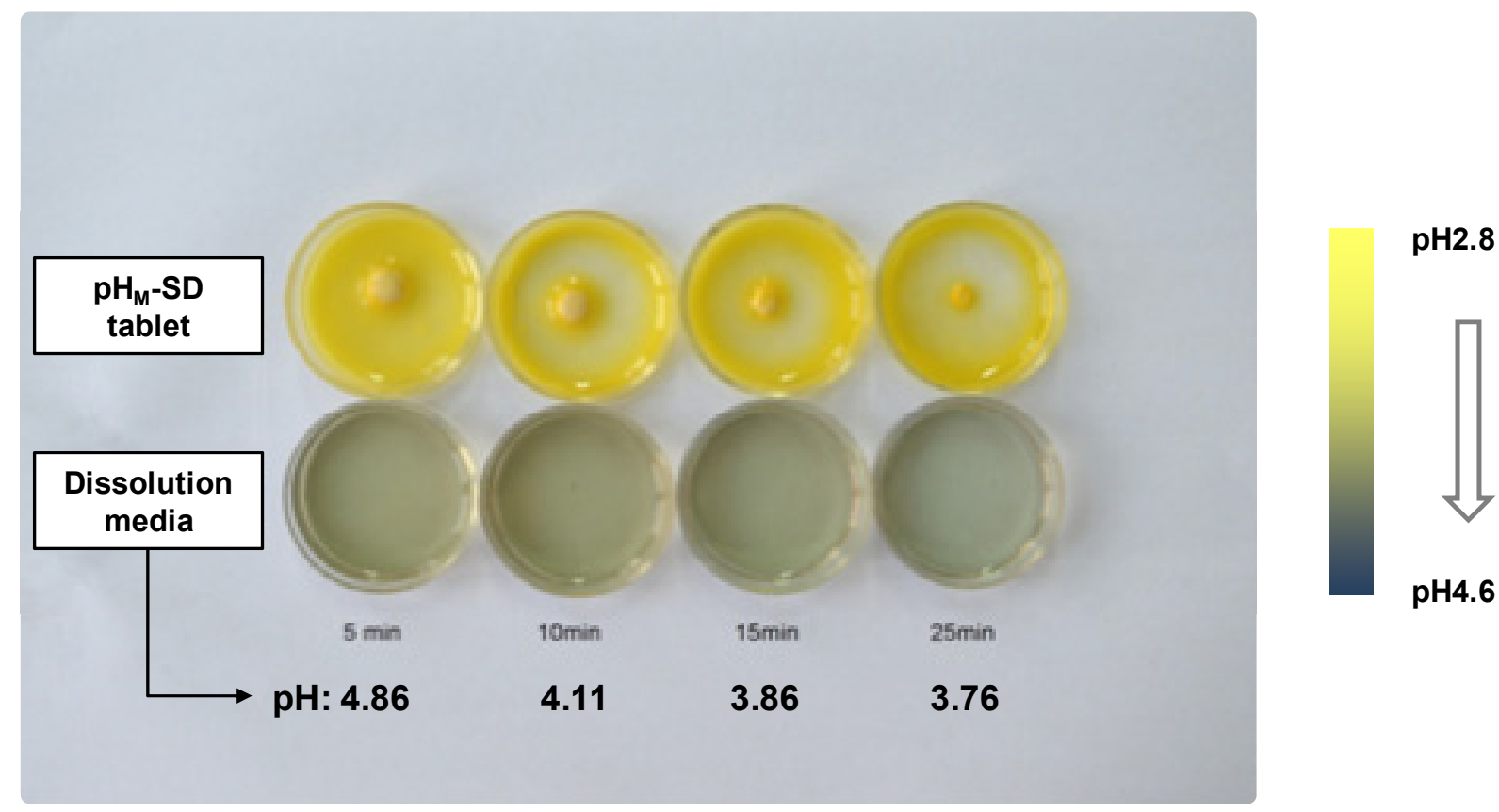

Figure 5. Color changes of $\mathrm{pH}_{\mathrm{M}}-\mathrm{SD}$ tablets and the dissolution media at different times with bromophenol blue as the indicator. 
During this process, the drug Griseofulvin crystals are formed first and serve as nuclei for the precipitation of the polymer Eudragit RL100, which forms a thin coating around the GF crystals (113).

\section{Supersaturated liposomes}

In recent years, liposomes have been attractive delivery systems in many fields, especially in cancer therapy because of their potential in targeting therapy. To lower the dosage and consequently reduce the toxicity, high drug loading is likely to be necessary $(114,115)$.

Liposomal drug loading can be achieved by either passive or active methods. Active loading, which is driven by a $\mathrm{pH}$ or potential gradient, has been proven to be more effective for achieving higher drug-to-lipid ratios compared to passive loading and is thus widely used for some weakly acidic or basic drugs (116). However, for some poorly water-soluble drugs, low solubility and the resulting low concentration gradient may cause insufficient driving force and a limited role in drug loading improvement. To enhance drug-to-lipid ratios for poorly soluble drugs, a novel method based on supersaturation using a small amount of cyclodextrin as the precipitation inhibitor for active drug loading was reported by Modi. The supersaturated solution of active drug AR-67 (camptothecin analog) was maintained for $48 \mathrm{~h}$ and was used to load the drug. The drug-loading was improved (drug/lipids ratio, 0.17 ), and the influence of the internal phase by calcium acetate or sodium acetate was small (117). The mechanism is shown in Fig. 6.

A novel drug-in-cyclodextrin-in-liposomes was prepared using the passive drug-loading method of thin film hydration to increase the bioavailability of the poorly soluble flurbiprofen by increasing the dissolved drug amount. The flurbiprofen cyclodextrin complexes were first prepared and then entrapped in the internal aqueous phase rather than the external bilayer of the liposomes. Entrapment of FP-HP- $\beta-C D$ into the liposomes did change the $\mathrm{T}_{\max }$ and improve the $\mathrm{C}_{\max }$ and bioavailability (118).
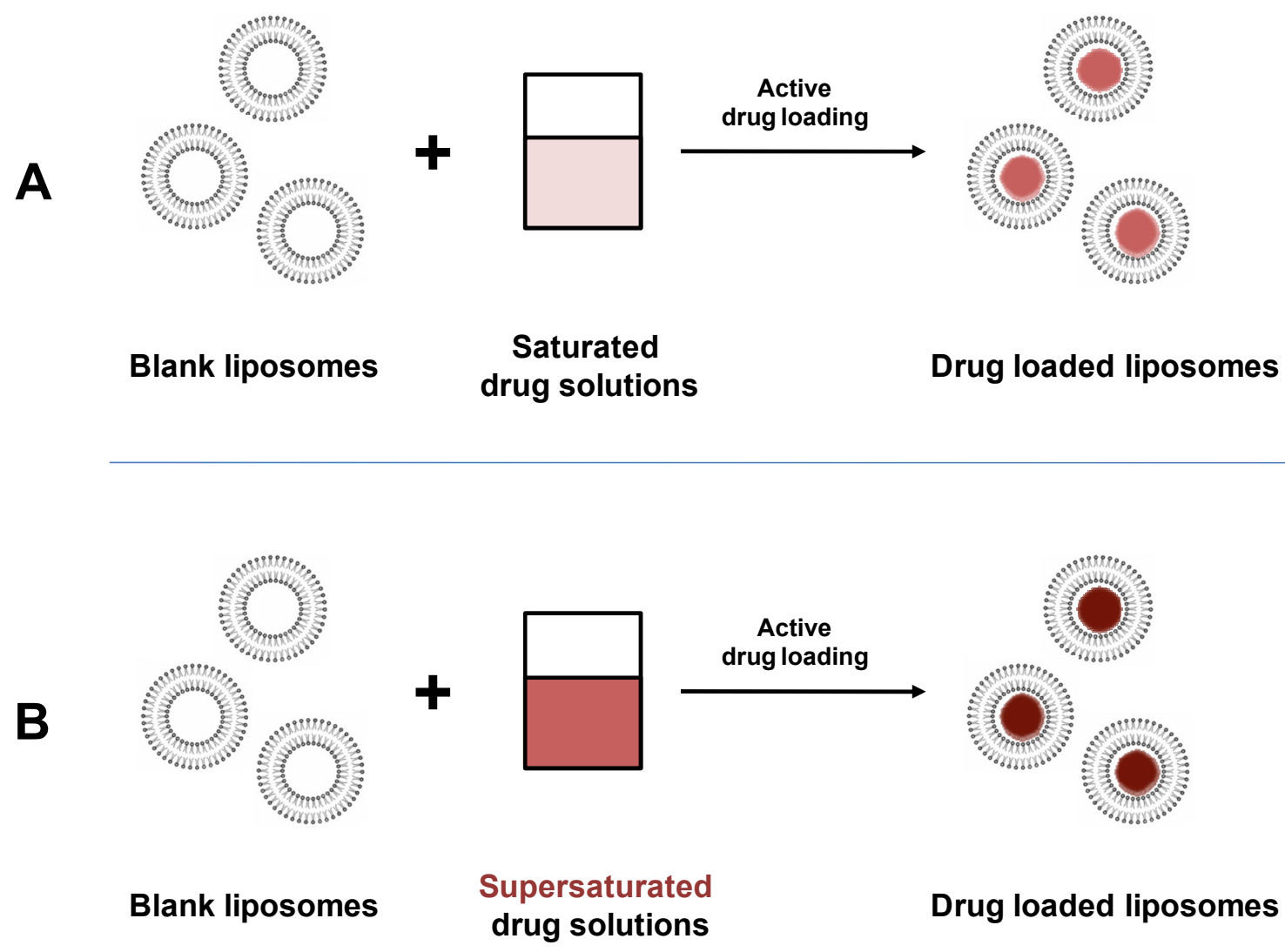

Figure 6. Illustration of the traditional active drug loading process (A) and supersaturated active drug loading process (B) of liposomes. The deeper the red color, the higher is the drug concentration. 


\section{Novel drug carrier materials}

\section{Ordered mesoporous silica}

According to the definition of the international union of pure and applied chemistry (IUPAC), mesoporous refers to a hole between $2 \sim 50 \mathrm{~nm}$. The adsorption of amorphous drugs on inorganic mesoporous materials can maintain the stability of the amorphous state due to the "finite - size effect". That is, when the size of the pore is reduced to the molecular level, the characteristics of the solid will change greatly (119). In the past decade, synthesis and application of mesoporous silica have received intensive attention due to their highly ordered structures, larger pore sizes, and high surface areas $(120,121)$ Ordered mesoporous silica (OMS) can be effectively used to generate and maintain supersaturation in the gastrointestinal tract for $\mathrm{pH}$-independent release and systemic exposure improvement $(27,122)$. Additionally, if poorly soluble drugs can be confined in the pores of a carrier, the drug can not only be delivered at the site of absorption but also be targeted to a specific site while being saved from any unwarranted degradation (4).

The commonly used OMS include SBA-15, MCM-41, FSM-16 (123).The surface area and pore size of the mesoporous silica is important for biotechnological and biomedical applications. Under sink conditions, the larger the pore is, the faster the drug release, whereas in biorelevant media, the degree of supersaturation and maintenance time increase with the increase in the pore size. In vivo pharmacokinetic results show that the larger the pore, the lower is the bioavailability. The reason is the slower drug release, the later the supersaturation is generated, which is beneficial for drug absorption (122).

For drug delivery based on OMS, several investigations using organic modified mesoporous silica have been reported. To promote the in vitro dissolution of the drug, HPMC and HPMCAS are commonly used as precipitation inhibitors with SBA-15 as the carrier material. Although HPMCAS can maintain drug supersaturation in intestinal fluid, the improvement of HPMCAS in vivo absorption is limited compared to HPMC due to its insolubility in the stomach (124).

The bioactivity of mesoporous silica material-based drug systems is an important factor for its potential application. The interactions between the OMS and physiological fluids are influenced by the chemical groups of the OMS (125). The mesoporous silica MCM-48, MCM-41, and SBA-15 are reported to be bioactive materials for the drug delivery system.
However, the biocompatibility is not very strong. Modification of silica with phosphorous material or active components such as hydroxyapatite will significantly improve its biocompatibility (121, 126).

\section{Other porous materials}

Other porous materials are also reported to be drug carriers. The CapsMorph ${ }^{\circledR}$ technology prepares amorphous drugs for oral delivery by encapsulating them in porous materials (AEROPERL ${ }^{\circledR} 300$ Pharma). The drug-loaded porous materials provide better formulations compared to nanocrystals for poorly soluble drugs (127).

A Soluplus-coated colloidal silica nanomatrix (SCCSN) was also used for the entrapment of poorly water-soluble drugs. The maximum supersaturation of the drug-loaded nanomatrix was higher than that of a physical mixture as indicated by the results of in vitro kinetic solubility studies (128).

\section{CONCLUSION}

In recent years, because of its role in the bioavailability improvement effect of poorly water-soluble drugs, strategies based on supersaturation have attracted increasing attention such that some products are now on the market (129). Of the above mentioned strategies, solid dispersions have been most extensively studied and are relatively easy to scale up. The liquid formulations, such as supersaturated self-emulsifying drug delivery systems, cyclodextrin complexes, liposomes and nanodrugs, are more or less faced with a stability problem and are limited in further application. Drug carrier materials provide a promising strategy to deliver the drug to the target, but other hurdles will need to be considered including the biocompatibility, toxicity, and functionality before this strategy can be applied as a real alternative in the pharmaceutical industry. The oral formulation design of poorly water-soluble drugs is affected by the following aspects: the introduction of novel experimental design methods such as "Formulation by design" methodology (130) and further understanding of the supersaturation mechanism.

\section{ACKNOWLEDGEMENTS}

This study was supported by the State key Laboratory of Toxicology and Medical Countermeasures and the National Key 
Technologies R\&D Program for New Drugs (Grant No. 2012ZX09301003-001-009).

\section{CONFLICT OF INTEREST}

The authors report no conflicts of interest.

\section{REFERENCES}

1. Bikiaris DN. Solid dispersions Part I: recent evolutions and future opportunities in manufacturing methods for dissolution rate enhancement of poorly water-soluble drugs. Expert Opin Drug Deliv 2011; 8:1501-1519.doi: 10.1517/17425247.2011.618181.

2. Cooper ER. Nanoparticles: A personal experience for formulating poorly water soluble drugs. J Control Release 2010;141:300-302.doi: 10.1016/j.jconrel.2009.10.006.

3. Lipinski CA, Lombardo F, Dominy BW, et al. Experimental and computational approaches to estimate solubility and permeability in drug discovery and development settings. Adv Drug Deliv Rev 2001;64:3-26

4. Singh A, Worku Z A, Van den Mooter G. Oral formulation strategies to improve solubility of poorly water-soluble drugs. Expert Opin Drug Deliv 2011; 8:1361-1378. doi: 10.1517/17425247.2011.606808.

5. Blagden N, de Matas M, Gavan PT, et al. Crystal engineering of active pharmaceutical ingredients to improve solubility and dissolution rates. Adv Drug Deliv Rev 2007; 59:617-630

6. Onoue S, Uchida A, Takahashi $\mathrm{H}$, et al. Development of high-energy amorphous solid dispersion of nanosized nobiletin a citrus polymethoxylated flavone with improved oral bioavailability. J Pharm Sci 2011;100:3793-3801. doi: $10.1002 /$ jps.22585.

7. Vasconcelos T, Sarmento B, Costa P. Solid dispersions as strategy to improve oral bioavailability of poor water soluble drugs. Drug Discov Today 2007; 12:1068-1075

8. Raina SA, Eerdenbrugh BV, Alonzo DE, et al. Trends in the precipitation and crystallization behavior of supersaturated aqueous solutions of poorly water-soluble drugs assessed using synchrotron radiation. J Pharm Sci 2015; 104:1981-1992. doi: 10.1002/jps.24423.

9. Fahr A, Liu X. Drug delivery strategies for poorly water-soluble drugs. Expert Opin. Drug Deliv 2007; 4:403-416

10. Brouwers J, Brewster ME, Augustijns P. Supersaturating drug delivery systems: the answer to solubility-limited oral bioavailability. J Pharm Sci 2009; 98:2549-2572. doi: 10.1002/jps.21650.

11. Reid ML, Jones SA, Brown MB. Transient drug supersaturation kinetics of beclomethasone dipropionate in rapidly drying films. Int J Pharm 2009;371:114-119.

doi:

10.1016/j.ijpharm.2008.12.025.

12. Giannola LI, Sutera FM, De Caro V. Physical methods to promote drug delivery on mucosal tissues of the oral cavity. Expert Opin Drug Deliv 2013; $10: 1449-1462$. doi: 10.1517/17425247.2013.809061.

13. Cilurzo F, Casiraghi A, Selmin F, et al. Supersaturation as a tool for skin penetration enhancement. Curr Pharm Des 2015;21:2733-2744

14. Donnelly RF, McCarron PA, Morrow DI, et al. Fast-drying multi-laminate bioadhesive films for transdermal and topical drug delivery. Drug Dev Ind Pharm 2013;39:1818-1831. doi: 10.3109/03639045.2012.738683.

15. Xu S, Dai WG. Drug precipitation inhibitors in supersaturable formulations. Int $\mathrm{J}$ Pharm 2013;453:36-43. doi: 10.1016/j.ijpharm.2013.05.013.

16. Frank KJ, Rosenblatt KM, Westedt U, et al. Amorphous solid dispersion enhances permeation of poorly soluble ABT-102: True supersaturation vs apparent solubility enhancement. Int J Pharm 2012;437:288-293.

doi: 10.1016/j.ijpharm.2012.08.014.

17. Ouellet D, Grossmann KF, Limentani G, et al. Effects of particle size food and capsule shell composition on the oral bioavailability of dabrafenib a BRAF inhibitor in patients with BRAF mutation-positive tumors. J Pharm Sci 2013;102:3100-3109. doi: 10.1002/jps.23519.

18. Berlin M, Ruff A, Kesisoglou F, et al. Advances and challenges in PBPK modeling - Analysis of factors contributing to the oral absorption of atazanavir a poorly soluble weak base. Eur J Pharm Biopharm 2015; 93:267-280. doi: 10.1016/j.ejpb.2015.03.031.

19. Polster CS, Wu SJ, Gueorguieva I, et al. Mechanism for enhanced absorption of a solid dispersion formulation of Ly2300559 using the artificial stomach duodenum model. Mol Pharm 2015; 12:1131-1140. doi: 10.1021/mp5006036.

20. Narang AS, Badawy S, Ye Q, et al. Role of self-association and supersaturation in oral absorption of a poorly soluble weakly basic drug. Pharm Res 2015; 32:2579-2594. doi: 10.1007/s11095-015-1645-y.

21. Guzmán HR, Tawa M, Zhang Z, et al. Combined use of crystalline salt forms and precipitation inhibitors to improve oral absorption of celecoxib from solid oral formulations. J Pharm Sci 2007;96:2686-2702

22. Sun DD, Lee PI. Evolution of supersaturation of amorphous pharmaceuticals: nonlinear rate of supersaturation generation regulated by matrix diffusion. Mol Pharm 2015; 12:1203-1215. doi: $10.1021 / \mathrm{mp} 500711 \mathrm{c}$. 
23. Chen Y, Liu C, Chen Z, et al. Drug-polymer-water interaction and its implication for the dissolution performance of amorphous solid dispersions. Mol Pharm 2015;12:576-589. doi: 10.1021/mp500660m.

24. Frank KJ, Locher K, Zecevic DE, et al. In vivo predictive mini-scale dissolution for weak bases: Advantages of $\mathrm{pH}$-shift in combination with an absorptive compartment. Eur J Pharm Sci 2014; 61:32-39. doi: 10.1016/j.ejps.2013.12.015.

25. Bevernage J, Brouwers J, Annaert P, et al. Drug precipitation-permeation interplay: supersaturation in an absorptive environment. Eur J Pharm Biopharm 2012;82:424-428. doi: 10.1016/j.ejpb.2012.07.009.

26. Miller JM, Beig A, Carr RA, et al. A win-win solution in oral delivery of lipophilic drugs: supersaturation via amorphous solid dispersions increases apparent solubility without sacrifice of intestinal membrane permeability. Mol Pharm 2012; 9:2009-2016. doi: 10.1021/mp300104s.

27. Mellaerts R, Mols R, Kayaert P, et al. Ordered mesoporous silica induces $\mathrm{pH}$-independent supersaturation of the basic low solubility compound itraconazole resulting in enhanced transepithelial transport. Int J Pharm 2008;357:169-179. doi: 10.1016/j.ijpharm.2008.01.049.

28. Chauhan H, Hui-Gu C, Atef E. Correlating the behavior of polymers in solution as precipitation inhibitor to its amorphous stabilization ability in solid dispersions. J Pharm Sci 2013; 102:1924-1935. doi: 10.1002/jps.23539.

29. Patel DD, Anderson BD. Effect of precipitation inhibitors on indomethacin supersaturation maintenance: mechanisms and modeling. Mol Pharm 2014;11:1489-1499. doi: 10.1021/mp400658k.

30. Yamashita $K$, Nakate $T$, Okimoto $K$, et al. Establishment of new preparation method for solid dispersion formulation of tacrolimus. Int $\mathrm{J}$ Pharm 2003;267:79-91

31. Schram CJ, Beaudoin SP, Taylor LS. Impact of polymer conformation on the crystal growth inhibition of a poorly water-soluble drug in aqueous solution. Langmuir 2015;31:171-179. doi: 10.1021/la503644m.

32. Higashino $\mathrm{H}$, Hasegawa $\mathrm{T}$, Yamamoto $\mathrm{M}$, et al. In vitro-in vivo correlation of the effect of supersaturation on the intestinal absorption of BCS Class 2 drugs. Mol Pharm 2014;11:746-754. doi: $10.1021 / \mathrm{mp} 400465 \mathrm{p}$.

33. Kostewicz ES, Abrahamsson B, Brewster M, et al. In vitro models for the prediction of in vivo performance of oral dosage forms. Eur J Pharm Sci 2014;57:342-366. doi: 10.1016/j.ejps.2013.08.024.

34. Mathias NR, Xu Y, Patel D. et al. Assessing the risk of $\mathrm{pH}$-dependent absorption for new molecular entities: a novel in vitro dissolution test physicochemical analysis and risk assessment strategy. Mol Pharm 2013;10:4063-4073. doi: 10.1021/mp400426f.

35. Berlin M, Przyklenk KH, Richtberg A, et al. Prediction of oral absorption of cinnarizine - a highly supersaturating poorly soluble weak base with borderline permeability. Eur J Pharm Biopharm 2014;88:795-806. doi: 10.1016/j.ejpb.2014.08.011.

36. Stillhart C, Dürr D, Kuentz M. Toward an improved understanding of the precipitation behavior of weakly basic drugs from oral lipid-based formulations. J Pharm Sci 2014; 103:1194-1203. doi: 10.1002/jps.23892.

37. Mitra A, Fadda HM.Effect of surfactants gastric emptying and dosage form on supersaturation of dipyridamole in an in vitro model simulating the stomach and duodenum. Mol Pharm 2014;11:2835-2844. doi: 10.1021/mp500196f.

38. Lee TW, Boersen NA, Yang G, et al. Evaluation of different screening methods to understand the dissolution behaviors of amorphous solid dispersions. Drug Dev Ind Pharm 2014;40:1072-1083. doi: 10.3109/03639045.2013.807279.

39. Frank KJ, Westedt U, Rosenblatt KM, et al. What is the mechanism behind increased permeation rate of a poorly soluble drug from aqueous dispersions of an amorphous solid dispersion? J Pharm Sci 2014;103:1779-1786. doi: 10.1002/jps.23979.

40. Anby MU, Nguyen TH, Yeap YY, et al. An in vitro digestion test that reflects rat intestinal conditions to probe the importance of formulation digestion vs first pass metabolism in Danazol bioavailability from lipid based formulations. Mol Pharm 2014;11:4069-4083. doi: 10.1021/mp500197b.

41. Williams HD, Sassene P, Kleberg K, et al. Toward the establishment of standardized in vitro tests for lipid-based formulations part 3: understanding supersaturation versus precipitation potential during the in vitro digestion of type I II IIIA IIIB and IV lipid-based formulations. Pharm Res 2013; 30:3059-3076. doi: 10.1007/s11095-013-1038-z.

42. Thomas N, Richter K, Pedersen TB, et al. In vitro lipolysis data does not adequately predict the in vivo performance of lipid-based drug delivery systems containing fenofibrate. AAPS J 2014;16:539-549. doi: 10.1208/s12248-014-9589-4.

43. Bevernage J, Brouwers J, Brewster ME, et al. Evaluation of gastrointestinal drug supersaturation and precipitation: Strategies and issues. Int $\mathrm{J}$ Pharm 2013; 453: 25-35. doi: 10.1016/j.ijpharm.2012.11.026.

44. Shah KB, Patel PG, Khairuzzaman A, et al. An 
improved method for the characterization of supersaturation and precipitation of poorly soluble drugs using pulsatile microdialysis (PMD). Int J Pharm 2014;468:64-74. doi: 10.1016/j.ijpharm.2014.04.012.

45. Raut S, Karzuon B, Atef E. Using in situ Raman spectroscopy to study the drug precipitation inhibition and supersaturation mechanism of Vitamin E TPGS from self-emulsifying drug delivery systems (SEDDS). J Pharm Biomed Anal 2015; 109:121-127. doi: 10.1016/j.jpba.2015.02.027.

46. Ueda K, Higashi K, Yamamoto $\mathrm{K}$, et al. Equilibrium state at supersaturated drug concentration achieved by hydroxypropyl methylcellulose acetate succinate: molecular characterization using (1)H NMR technique. Mol Pharm 2015;12:1096-1104. doi: $10.1021 / \mathrm{mp} 500588 \mathrm{x}$.

47. Morrison JS, Nophsker MJ, Haskell RJ. A combination turbidity and supernatant microplate assay to rank-order the supersaturation limits of early drug candidates. J Pharm Sci 2014;103:3022-3032. doi: 10.1002/jps.24090.

48. Stappaerts J, Geboers S, Snoeys J, et al. Rapid conversion of the ester prodrug abiraterone acetate results in intestinal supersaturation and enhanced absorption of abiraterone: in vitro rat in situ and human in vivo studies. Eur $\mathrm{J}$ Pharm Biopharm 2015; 90:1-7. doi: 10.1016/j.ejpb.2015.01.001.

49. Brouwers J, Augustijns P. Resolving intraluminal drug and formulation behavior: Gastrointestinal concentration profiling in humans. Eur J Pharm Sci 2014; 61:2-10. doi: 10.1016/j.ejps.2014.01.010.

50. Kawakami K. Modification of physicochemical characteristics of active pharmaceutical ingredients and application of supersaturatable dosage forms for improving bioavailability of poorly absorbed drugs. Adv Drug Deliv Rev 2012; 64:480-495. doi: 10.1016/j.addr.2011.10.009.

51. Newman A, Nagapudi K, Wenslow R. Amorphous solid dispersions: a robust platform to address bioavailability challenges. Ther Deliv 2015; 6:247-261. doi: 10.4155/tde.14.101.

52. Verma S, Rudraraju VS. Disintegration mediated controlled release supersaturating solid dispersion formulation of an insoluble drug: design development optimization and in vitro evaluation. AAPS PharmSciTech 2015;16:85-97. doi: 10.1208/s12249-014-0187-7.

53. Yang $Z$, Nollenberger $K$, Albers $J$, et al. Molecular implications of drug-polymer solubility in understanding the destabilization of solid dispersions by milling. Mol Pharm 2014; 11:2453-2465. doi: 10.1021/mp500205c.

54. Vo CL, Park C, Lee BJ. Current trends and future perspectives of solid dispersions containing poorly water-soluble drugs. Eur J Pharm Biopharm 2013;85:799-813. doi: 10.1016/j.ejpb.2013.09.007.

55. Mosquera-Giraldo LI, Taylor LS. Glass-liquid phase separation in highly supersaturated aqueous solutions of telaprevir. Mol Pharm 2015;12:496-503. doi: 10.1021/mp500573z.

56. Raina SA, Zhang GG, Alonzo DE, et al. Enhancements and limits in drug membrane transport using supersaturated solutions of poorly water soluble drugs. J Pharm Sci 2014; 103:2736-2748. doi: 10.1002/jps.23826.

57. Jackson MJ, Toth SJ, Kestur US, et al. Impact of polymers on the precipitation behavior of highly supersaturated aqueous danazol solutions. Mol Pharm 2014;11:3027-3038. doi: $10.1021 / \mathrm{mp} 500201 \mathrm{~s}$.

58. Sotthivirat S, McKelvey C, Moser J, et al. Development of amorphous solid dispersion formulations of a poorly water-soluble drug MK-0364. Int J Pharm 2013; 452:73-81. doi: 10.1016/j.ijpharm.2013.04.037.

59. Janssens S, Nagels S, Armas HN, et al. Formulation and characterization of ternary solid dispersions made up of Itraconazole and two excipients, TPGS 1000 and PVPVA 64, that were selected based on a supersaturation screening study. Eur J Pharm Biopharm 2008; 69:158-166. doi: 10.1016/j.ejpb.2007.11.004.

60. Verma S, Rudraraju VS. Wetting kinetics: an alternative approach towards understanding the enhanced dissolution rate for amorphous solid dispersion of a poorly soluble drug. AAPS PharmSciTech 2015; 16(5):1079-1090. doi: 10.1208/s12249-014-0281-x.

61. Sun DD, Lee PI. Evolution of supersaturation of amorphous pharmaceuticals: the effect of rate of supersaturation generation. Mol Pharm 2013; 10:4330-4346. doi: 10.1021/mp400439q.

62. Curatolo W, Nightingale JA, Herbig SM. Utility of hydroxypropylmethylcellulose acetate succinate (HPMCAS ) for initiation and maintenance of drug supersaturation in the GI milieu. Pharm Res 2009; 26:1419-1431. doi: 10.1007/s11095-009-9852-z.

63. Dalsin MC, Tale S, Reineke TM. Solution-state polymer assemblies influence BCS class II drug dissolution and supersaturation maintenance. Biomacromolecules 2014;15:500-511. doi: 10.1021/bm401431t.

64. Zecevic DE, Meier R, Daniels R, et al. Site specific solubility improvement using solid dispersions of HPMC-AS/HPC SSL-mixtures. Eur J Pharm Biopharm 2014; 87:264-270. doi: 10.1016/j.ejpb.2014.03.018.

65. Prasad D, Chauhan H, Atef E. Amorphous stabilization and dissolution enhancement of amorphous ternary solid dispersions: combination of polymers showing drug-polymer interaction 
for synergistic effects. J Pharm Sci 2014;103:3511-3523. doi: 10.1002/jps.24137.

66. Sarode AL, Sandhu H, Shah N, et al. Hot melt extrusion for amorphous solid dispersions: temperature and moisture activated drug-polymer interactions for enhanced stability. Mol Pharm 2013;10:3665-3675. doi: 10.1021/mp400165b.

67. Chen YL, Liao JB, Liang YZ, et al. Characterization of solid dispersions of Patchouli alcohol with different polymers: effects on the inhibition of reprecipitation and the improvement of dissolution rate. Drug Dev Ind Pharm 2015; 41:436-444.

doi: 10.3109/03639045.2013.877482.

68. Kim MS, Baek IH. Fabrication and evaluation of valsartan-polymer- surfactant composite nanoparticles by using the supercritical antisolvent process. Int $\mathrm{J}$ Nanomedicine 2014;9:5167-5176. doi: 10.2147/IJN.S71891.

69. Nguyen DN, Van den Mooter G. The fate of ritonavir in the presence of darunavir. Int J Pharm 2014;475:214-226. doi: 10.1016/j.ijpharm.2014.08.062.

70. Sarode AL, Malekar SA, Cote C, et al. Hydroxypropyl cellulose stabilizes amorphous solid dispersions of the poorly water soluble drug felodipine. Carbohydr Polym 2014; 112:512-519. doi: 10.1016/j.carbpol.2014.06.039.

71. Sarode AL, Wang $P$, Obara $S$, et al. Supersaturation nucleation and crystal growth during single- and biphasic dissolution of amorphous solid dispersions: polymer effects and implications for oral bioavailability enhancement of poorly water soluble drug. Eur J Pharm Biopharm 2014; 86:351-360. doi: 10.1016/j.ejpb.2013.10.005.

72. Knopp MM. Olesen NE. Holm P, et al. Evaluation of drug-polymer solubility curves through formal statistical analysis: comparison of preparation techniques. J Pharm Sci 2015; 104:44-51. doi: 10.1002/jps.24207.

73. Wikene KO, Hegge AB, Bruzell E, et al. Formulation and characterization of lyophilized curcumin solid dispersions for antimicrobial photodynamic therapy (aPDT): studies on curcumin and curcuminoids LII. Drug Dev Ind Pharm 2015; 41:969-977. doi: 10.3109/03639045.2014.919315.

74. Cheow WS, Kiew TY, Yang Y, et al. Amorphization strategy affects the stability and supersaturation profile of amorphous drug nanoparticles. Mol Pharm 2014;11:1611-1620. doi: 10.1021/mp400788p.

75. Bennett RC, Brough C, Miller DA, et al. Preparation of amorphous solid dispersions by rotary evaporation and KinetiSol Dispersing: approaches to enhance solubility of a poorly water-soluble gum extract. Drug Dev Ind Pharm 2015; 41:382-397. doi:
10.3109/03639045.2013.866142.

76. Dokania S, Joshi AK. Self-microemulsifying drug delivery system (SMEDDS) - challenges and road ahead. Drug Deliv 2015;22:675-690. doi: 10.3109/10717544.2014.896058.

77. Gao P, Rush BD, Pfund WP, et al. Development of a supersaturable SEDDS (SSEDDS) formulation of paclitaxel with improved oral bioavailability. J Pharm Sci 2003;92:2386-2398

78. Gao P, Morozowich W. Development of supersaturatable self-emulsifying drug delivery system formulations for improving the oral absorption of poorly soluble drugs. Expert Opin Drug Deliv 2006; 3:97-110

79. Gao P, Guyton ME, Huang T, et al. Enhanced oral bioavailability of a poorly water soluble drug PNU-91325 by supersaturatable formulations. Drug Dev Ind Pharm 2004;30:221-229

80. Gao P, Akrami A, Alvarez F, et al. Characterization and optimization of AMG 517 supersaturatable self-emulsifying drug delivery system (S-SEDDS) for improved oral absorption. J Pharm Sci 2009; 98:516-528. doi: 10.1002/jps.21451.

81. Chen ZQ, Liu Y, Zhao JH, et al. Improved oral bioavailability of poorly water-soluble indirubin by a supersaturatable self-microemulsifying drug delivery system. Int J Nanomedicine 2012; 7:1115-1125. doi: 10.2147/IJN.S28761.

82. Bandyopadhyay S, Katare OP, Singh B. Development of optimized supersaturable self-nanoemulsifying systems of ezetimibe: effect of polymers and efflux transporters. Expert Opin Drug Deliv 2014; 11 479-492. doi: 10.1517/17425247.2014.877885.

83. Zhang N, Zhang W, Jin Y, et al. Studies on preparation of carbamazepine (CBZ ) supersaturatable self-microemulsifying (S-SMEDDS ) formulation and relative bioavailability in beagle dogs. Pharm Dev Technol 2011;16:415-421. doi: 10.3109/10837451003774419.

84. Singh G, Pai RS. In vitro and in vivo performance of supersaturable self-nanoemulsifying system of trans-resveratrol. Artif Cells Nanomed Biotechnol 2016 ; 44:510-6. doi: 10.3109/21691401.2014.966192.

85. Arima H, Hayashi Y, Higashi T, et al. Recent advances in cyclodextrin delivery techniques. Expert Opin Drug Deliv 2015; 12:1425-1441. doi: 10.1517/17425247.2015.1026893.

86. Sharma N, Baldi A. Exploring versatile applications of cyclodextrins: an overview. Drug Deliv $2016 \quad ; 23: 739-57 . \quad$ doi: 10.3109/10717544.2014.938839.

87. Loftsson T, Duchêne D. Cyclodextrins and their pharmaceutical applications. Int J Pharm 2007; 329:1-11

88. Brewster ME, Loftsson T. Cyclodextrins as 
pharmaceutical solubilizers. Adv Drug Deliv Rev 2007; 59:645-666

89. Gabelica V, Galic N, De Pauw E. On the specificity of cyclodextrin complexes detected by electrospray mass spectrometry. J Am Soc Mass Spectrom 2002;13:946-953

90. Loftsson $\mathrm{T}$, Másson $\mathrm{M}$, Brewster $\mathrm{ME}$. Self-association of cyclodextrins and cyclodextrin complexes. J Pharm Sci 2004;93:1091-1099

91. Brewster ME, Vandecruys R, Peeters J, et al. Comparative interaction of 2-hydroxypropyl-beta-cyclodextrin and sulfobutylether-beta-cyclodextrin with itraconazole: Phase-solubility behavior and stabilization of supersaturated drug solutions. Eur J Pharm Sci 2008;34:94-103. doi: 10.1016/j.ejps.2008.02.007.

92. di Cagno M, Terndrup Nielsen T, Lambertsen Larsen $\mathrm{K}$, et al. $\beta$-Cyclodextrin-dextran polymers for the solubilization of poorly soluble drugs. Int J Pharm 2014;468:258-263. doi: 10.1016/j.ijpharm.2014.04.029.

93. Möschwitzer JP. Drug nanocrystals in the commercial pharmaceutical development process. Int J Pharm 2013; 453:142-156. doi: 10.1016/j.ijpharm.2012.09.034.

94. Dias MM, Raghavan SL, Pellett MA, et al. The effect of beta-cyclodextrins on the permeation of diclofenac from supersaturated solutions. Int $\mathrm{J}$ Pharm 2003;263:173-181

95. Loftsson $\mathrm{T}$, Magnúsdóttir $\mathrm{A}$, Másson $\mathrm{M}$, et al. Self-association and cyclodextrin solubilization of drugs. J Pharm Sci 2002;91:2307-2316

96. Taniguchi C, Kawabata Y, Wada K, et al. Microenvironmental $\mathrm{pH}$-modification to improve dissolution behavior and oral absorption for drugs with pH-dependent solubility. Expert Opin Drug Deliv 2014; 11:505-516. doi: 10.1517/17425247.2014.881798.

97. Siepe S, Lueckel B, Kramer A, et al. Strategies for design of hydrophilic matrix tablets with controlled microenvironmental $\mathrm{pH}$. Int J Pharm 2006;316:14-20

98. Badawy SI, Gray DB, Zhao F, et al. Formulation of solid dosage forms to overcome gastric $\mathrm{pH}$ interaction of the factor $\mathrm{Xa}$ inhibitor BMS-561389. Pharm Res 2006; 23:989-996

99. Zannou EA, Ji Q, Joshi YM, et al. Stabilization of maleate salt of a basic drug by adjustment of microenvironmental $\mathrm{pH}$ in solid dosage form. Int J Pharm 2007; 337:210-218

100. Gao P, Shi Y. Characterization of supersaturatable formulations for improved absorption of poorly soluble drugs. AAPS J 2012;14:703-713. doi: 10.1208/s12248-012-9389-7.

101. Yang M, He S, Fan Y, et al. Microenvironmental $\mathrm{pH}$-modified solid dispersions to enhance the dissolution and bioavailability of poorly water-soluble weakly basic GT0918 a developing anti-prostate cancer drug: Preparation characterization and evaluation in vivo. Int $\mathrm{J}$ Pharm 2014; 475:97-109. doi: 10.1016/j.ijpharm.2014.08.047.

102. Bi M, Kyad A, Alvarez-Nunez F, et al. Enhancing and sustaining AMG 009 dissolution from a bilayer oral solid dosage form via microenvironmental $\mathrm{pH}$ modulation and supersaturation. AAPS PharmSciTech 2011; 12:1401-1406. doi: 10.1208/s12249-011-9710-2.

103. Doherty $\mathrm{C}$, York $\mathrm{P}$. In vitro $\mathrm{pH}$ dissolution dependence and in vivo bioavailability of frusemide-PVP solid dispersions. J Pharm Pharmacol 1989;41:73-78

104. Ige PP, Baria RK, Gattani SG. Fabrication of fenofibrate nanocrystals by probe sonication method for enhancement of dissolution rate and oral bioavailability. Colloids Surf B Biointerfaces 2013; 108:366-373.

doi: 10.1016/j.colsurfb.2013.02.043.

105. Leone F, Cavalli R. Drug nanosuspensions: a ZIP tool between traditional and innovative pharmaceutical formulations. Expert Opin Drug Deliv 2015; 12(10):1607-1625. doi: 10.1517/17425247.2015.1043886.

106. D'Addio SM, Prud'homme RK. Controlling drug nanoparticle formation by rapid precipitation. Adv Drug Deliv Rev 2011;63:417-426. doi: 10.1016/j.addr.2011.04.005.

107. Pawar VK, Singh Y, Meher JG, et al. Engineered nanocrystal technology: In-vivo fate targeting and applications in drug delivery. J Control Release 2014;183:51-66.

doi: 10.1016/j.jconrel.2014.03.030.

108. Dalvi SV, Dave RN. Analysis of nucleation kinetics of poorly water-soluble drugs in presence of ultrasound and hydroxypropyl methyl cellulose during antisolvent precipitation. Int J Pharm 2010; 387:172-179.

doi: 10.1016/j.ijpharm.2009.12.026.

109. Mugheirbi NA, Paluch KJ, Tajber L. Heat induced evaporative antisolvent nanoprecipitation (HIEAN) of itraconazole. Int $\mathrm{J}$ Pharm 2014;471:400-411. doi: 10.1016/j.ijpharm.2014.05.045.

110. Zhai X, Lademann J, Keck CM, et al. Nanocrystals of medium soluble actives-novel concept for improved dermal delivery and production strategy. Int J Pharm 2014;470:141-150. doi: 10.1016/j.ijpharm.2014.04.060.

111. Yue PF, Li Y, Wan J, et al. Study on formability of solid nanosuspensions during nanodispersion and solidification: Novel role of stabilizer/drug property. Int J Pharm 2013;454:269-277. doi: 10.1016/j.ijpharm.2013.06.050.

112. Kiew TY, Cheow WS, Hadinoto K. Preserving the supersaturation generation capability of 
amorphous drug-polysaccharide nanoparticle complex after freeze drying. Int $\mathrm{J}$ Pharm 2015;484:115-123. doi: 10.1016/j.ijpharm.2015.02.057.

113. Chen D, Singh D, Sirkar KK, et al. Continuous synthesis of polymer-coated drug particles by porous hollow fiber membrane-based antisolvent crystallization. Langmuir 2015; 31:432-441. doi: 10.1021/la503179t.

114. Barenholz Y. Relevancy of drug loading to liposomal formulation therapeutic efficacy. J Liposome Res 2003; 13:1-8

115. Fenske DB, Chonn A, Cullis PR. Liposomal nanomedicines: an emerging field .Toxicol Pathol 2008;36:21-29. doi: 10.1177/0192623307310960.

116. Gubernator J. Active methods of drug loading into liposomes: recent strategies for stable drug entrapment and increased in vivo activity. Expert Opin Drug Deliv 2011;8:565-580. doi: 10.1517/17425247.2011.566552.

117. Modi S, Xiang TX, Anderson BD, et al. Enhanced active liposomal loading of a poorly soluble ionizable drug using supersaturated drug solutions. J Control Release 2012;162:330-339. doi: 10.1016/j.jconrel.2012.07.001.

118. Zhang L, Zhang Q, Wang $X$, et al. Drug-in-cyclodextrin-in-liposomes: A novel drug delivery system for flurbiprofen. Int $\mathrm{J}$ Pharm 2015;492:40-45.

doi: 10.1016/j.ijpharm.2015.07.011.

119. Alcoutlabi M, McKenna GB. Effects of confinement on material behavior at the nanometer size scale. J Phys Condens Ma 2005; 17:461-524

120. Scott BJ, Wirnsberger G, Stucky GD. Mesoporous and mesostructured materials for optical applications. Chem Mater 2001;13:3140-3150

121. Safari J, Zarnegar Z. Advanced drug delivery systems: Nanotechnology of health design A review. J Saudi Chem Society 2014; 18:85-99.doi:10.1016/j.jscs.2012.12.009.
122. van Speybroeck M, Mellaerts R, Mols R, et al. Enhanced absorption of the poorly soluble drug fenofibrate by tuning its release rate from ordered mesoporous silica. Eur J Pharm Sci 2010; 41:623-630. doi: 10.1016/j.ejps.2010.09.002.

123. Zhao D, Feng J, Huo Q, et al. Triblock copolymer syntheses of mesoporous silica with periodic 50-300 angstrom pores. Science 1998; 279:548-552

124. van Speybroeck M, Mols R, Mellaerts R, et al. Combined use of ordered mesoporous silica and precipitation inhibitors for improved oral absorption of the poorly soluble weak base itraconazole. Eur J Pharm Biopharm 2010; 75:354-365. doi: 10.1016/j.ejpb.2010.04.009.

125. Manzano M, Vallet-Regi MA. New developments in ordered mesoporous materials for drug delivery. J Mater Chem 2010;20:5593-604.doi: 10.1039/B922651F.

126. Huang S, Li C, Cheng Z, et al. Magnetic Fe304@mesoporous silica composites for drug delivery and bioadsorption. J Colloid Interface Sci 2012;376:312-321. doi: 10.1016/j.jcis.2012.02.031.

127. Wei Q, Keck CM, Müller RH. CapsMorph ${ }^{\circledR}$ technology for oral delivery-theory preparation and characterization. Int J Pharm 2015;482:11-20. doi: 10.1016/j.ijpharm.2014.10.068.

128. Kim MS. Soluplus-coated colloidal silica nanomatrix system for enhanced supersaturation and oral absorption of poorly water-soluble drugs. Artif Cells Nanomed Biotechnol 2013; 41:363-367. doi: $10.3109 / 21691401.2012 .762369$.

129. van Hoogevest P, Liu X, Fahr A. Drug delivery strategies for poorly water-soluble drugs: the industrial perspective. Expert Opin Drug Deliv 2011; 8(11):1481-1500. doi: 10.1517/17425247.2011.614228.

130. Singh B, Kapil R, Nandi M, et al. Developing oral drug delivery systems using formulation by design: vital precepts, retrospect and prospects. Expert Opin Drug Deliv 2011; 8: 1341-1360. doi: $10.1517 / 17425247.2011 .605120$. 